\section{Butterfly and Renal Cell Cancer: Out of Chaos Comes Order}

To the EDIToR: You are no doubt familiar with the butterfly effect paradigm to describe the chaos theory. The proverbial butterfly flaps its wings on a remote Caribbean island and causes a hurricane in Europe a few weeks later. A small change in one place can cause widely diverging outcomes in another. In patients with cancer the butterfly effect can have devastating effects. Over our many years of treating cancer, it has become evident that not everything can be anticipated/predicted but our ultimate goal remains unchanged. It has been said that 'out of chaos comes order'. We believe at this important juncture, treatment of renal cell carcinoma (RCC) requires "order" to be restored.

We have a veritable smorgasbord of potential therapeutic agents but we are at a loss how best to use them. Three recent papers in the journal- two clinical trial reports and one opinion piece- highlight the ongoing dilemmas in RCC management. ${ }^{1-3}$ Hwang and Heath ${ }^{1}$ reviewed results of recent trials and discussed their implications within the framework of a clinical case with the aim of defining a treatment algorithm. They suggest a second tyrosine kinase inhibitor (TKI) following an initial response of greater than 6 months and a mammalian target of rapamycin when response is less than 6 months. While this approach is not without its merits, the heterogeneity of RCC and the lack of comparative data make one hesitate to advocate its widespread adoption.

To comment on the detail—we acknowledge that pazopanib might be considered over sunitinib due to its better tolerability but the lack of data on the former in a patient population with sarcomatoid features, brain metastases or with no previous nephrectomy, suggests that in these subgroups of patients sunitinib is the preferred treatment approach. We agree that temsirolimus should be considered as standard in poor-risk patients, but that sunitinib is a good alternative particularly in patients with normal lactate dehydrogenase and those with symptoms due to tumor burden, as sunitinib can shrink the tumor and provide symptomatic relief.

We also consider that the duration of response should be viewed as a prognostic not a predictive factor to be used in determining second-line therapy. A prolonged response to a TKI is potentially associated with a better outcome, independently of subsequent therapies. Patients, who have no response or a short response to a first TKI, in general have a more aggressive disease and as such may benefit less from subsequent therapy. In our everyday clinical practice we consider comorbidities and tolerability of first-line agents when deciding second-line agents. In addition, in primary resistant patients, we believe that a more potent TKI such as axitinib, or a chemotherapy regimen, are more appropriate treatment options. Finally it should not be forgotten that three or more lines of therapy might be used in patients with slow, progressive disease.

These are details but to restore order one needs to consider the bigger picture-what is the overall message we should be giving to practicing clinicians on how to manage metastatic RCC and how to get the best out of the plethora of new therapeutic agents? Should we be developing more and more complex algorithms with the risk of adding to the "chaos" or would it be opportune, as advocated by our compatriot, ${ }^{4}$ to take this opportunity for simplification? The recommendation by Chris Ryan at American Society of Clinical Oncology nearly 5 years ago now, "... use any agent you want, but use it well ...," still holds true today.

We consider what there are no inherent wrong choices in the use of agents to treat RCC, only ways to use them better. Using them better includes toxicity management so that effective dosages of the chosen agent(s) can be administered-which can be argued is more important than the choice of agent.

\section{Giuseppe Procopio, Elena Verzoni, and Filippo De Braud \\ Fondazione Istituto Nazionale Tumori, Milan, Italy}

\section{AUTHORS' DISCLOSURES OF POTENTIAL CONFLICTS OF INTEREST}

Disclosures provided by the authors are available with this article at www.jco.org.

\section{REFERENCES}

1. Hwang $\mathrm{C}$, Heath $\mathrm{El}$ : The judgment of Paris: Treatment dilemmas in advanced renal cell carcinoma. J Clin Oncol 32:729-734, 2014

2. Rini BI, Bellmunt J, Clancy J, et al: Randomized phase III trial of temsirolimus and bevacizumab versus interferon alfa and bevacizumab in metastatic renal cell carcinoma: INTORACT Trial. J Clin Oncol 32:752-759, 2014

3. Hutson TE, Escudier B, Esteban E, et al: Randomized phase III trial of temsirolimus versus sorafenib as second-line therapy after sunitinib in patients with metastatic renal cell carcinoma. J Clin Oncol 32:760-767, 2014

4. Porta C: Entropy increases in kidney cancer treatment, but a bit of simplicity may emerge from chaos. Eur Urol 60:1171-1172, 2011

5. Ryan CW: Systemic therapies in advanced renal cell cancer: Current status. Presented at the 46th Annual Meeting of the American Society of Clinical Oncology, Chicago, IL, June 4-8, 2010

DOI: 10.1200/JCO.2014.56.4757; published online ahead of print at www.jco.org on July 28, 2014 


\section{AUTHORS' DISCLOSURES OF POTENTIAL CONFLICTS OF INTEREST}

\section{Butterfly and Renal Cell Cancer: Out of Chaos Comes Order}

The following represents disclosure information provided by authors of this manuscript. All relationships are considered compensated. Relationships are self-held unless noted. I = Immediate Family Member, Inst = My Institution. For a detailed description of the disclosure categories, or for more information about ASCO's conflict of interest policy, please refer to the Author Disclosure Declaration and the Disclosures of Potential Conflicts of Interest section in Information for Contributors.

\section{Giuseppe Procopio}

Consulting or Advisory Role: Astellas Pharma, Bayer, GlaxoSmithKline, Pfizer

\section{Elena Verzoni}

No relationship to disclose

\section{Filippo De Braud}

No relationship to disclose 